\title{
EL PATRONAZGO EN LAS IGLESIAS DE LA NUEVA ESPANA. DOCUMENTOS SOBRE LA COMPANIA DE JESÚS EN ZACATECAS EN EL SIGLO XVII
}

Por Marco Diaz

La marcada diferencia que existe entre el arte monástico y las obras de los siglos barrocos se debe en gran parte al cambio de los comanditarios de unas y otras obras.

Durante los primeros años de vida de la Nueva España el papel de los encomenderos y caciques es el de simples patrocinadores de las construcciones y son los frailes los que manifiestan sus necesidades espirituales en sus preferencias estéticas que van de la más desnuda sencillez a la más intrincada complejidad simbólica.

Hacia el último tercio del siglo xvi operaron trascendentes cambios en la estructura religiosa y económica de la Nueva España, los frailes pierden su importancia y son sustituidos por el clero secular, el nombramiento de Pedro Moya de Contreras como arzobispo de México acelera el proceso que destituye y margina a los frailes como pastores de las almas.

La presencia de los jesuitas a partir de esos años coopera a la modificación de las formas de vida que se habian practicado en el primer medio siglo de vida de la Nueva España.

La sustitución de las encomiendas por los repartimientos hace perder poder económico a los encomenderos y caciques y resquebraja la estructura que había tenido una vigencia similar a la del poder de los frailes.

El nuevo clero logra, a través de la institución del patronazgo, allegarse los medios para sus campañas constructivas. Son múltiples las causas para la aceptación de la responsabilidad que trae consigo este compromiso. Por un lado la búsqueda de prestigio social y por el otro la expresión de agradecimiento a Dios por los bienes recibidos. Los mineros enriquecidos a veces fortuita $e$ inesperadamente, los ricos comerciantes o los funcionarios reales se autopostulan como patronos de las ambiciosas campañas institucionales y constructivas de los nuevos conductores de los espíritus.

La institución del patronazgo estaba reglamentada ante el notario eclesiástico y en un contrato se declaraban las obligaciones y beneficios.

Las obligaciones consistían en cubrir el monto estipulado para la construcción del templo y la dotación de rentas, y entre los beneficios 
se contaban las misas, la entrega de la candela en las festividades más importantes, el derecho de enterrarse en el templo y el de colocar el escudo de armas en la portada. Estas distinciones de orden espiritual y social eran de capital importancia dentro del tipo de vida de la Nueva España.

Aunque no está consignado entre las prerrogativas que los patronos tenian, existia la posibilidad de elegir a los artistas que habian de realizar las obras y la de sugerir las formas y el contenido de las mismas.

Los patrones se convierten entonces en verdaderos mecenas del arte de la Nueva España, pues con su generosidad se erigieron las más grandes y ricas iglesias, los más bellos retablos, con su patrocinio los claustros se llenaron de pinturas de los más famosos maestros y los orfebres dotaron a la liturgia de mangníficos ornamentos.

La tierra, la mina o el comercio entregaban su riqueza a través del patrón para que bajo su influjo ésta se convirtiera en realizaciones artísticas.

Las obras de este tardío siglo xvi y las de los siglos posteriores nos revelan la participación de los patronos en la adopción de los recursos expresivos más novedosos que sustituyen a los modelos de que se habfan valido los frailes para sus obras.

Este proceso se observa con claridad en las realizaciones citadinas y en algunas de las más importantes poblaciones del interior donde el cambio del plateresco hacia las obras manieristas indica una modificación de los gustos artísticos. La proliferación de la pintura de caballete revela un cambio en las preferencias estéticas y el gran auge de los talleres confirma esa necesidad de modificación.

Los testimonios de ese anhelo están diseminados en múltiples fuentes impresas y los archivos guardan todavía inmensas posibilidades para conocer ese proceso. Los documentos que publicamos nos revelan la participación del patrono en el templo de la Compañía de Zacatecas.

El colegio fue fundado en 1616 y su iglesia fue terminada hacia 1625. Esta institución fue patrocinada por el maestro de campo don Vicente de Saldivar y su mujer Ana de Bañuelos, ambos descendientes de los primeros colonos del Real de Minas de Nuestra Señora de los Zacatecas. ${ }^{1}$

El templo que sólo conocemos a través de las breves menciones de las crónicas y por un grabado de 1732 se nos manifiesta como una

1 Francisco Javier Alegre. Historia de la Provincia de la Compañia de Jestís de Nueva España. Roma, Institutum Historicum S. J., 1956, II, 269. 
construcción rectangular con cubierta inclinada y una sola torre a los pies. ${ }^{2}$

Los documentos que acompañan este estudio ${ }^{3}$ nos permiten ampliar el conocimiento de esta obra y sobre todo puntualizar la participación del patrono en su ornamentación.

El primer documento fechado en 1625 nos ilustra del complicado tipo de gestiones que se hacian desde un lugar tan remoto como Zacatecas para procurarse algunos de los elementos del templo, como el retablo, la clavazón de las dos puertas, los escudos fundidos y las esculturas.

El segundo documento es la relación de los gastos que para la terminación de la obra se hicieron en ese año en ellos, se incluye una elevada cifra para la madera y la obra de carpinteria, se consigna también el precio de la cubierta de plomo y los costos para el avío de las dos puertas del templo, se incluyen los precios del retablo, del sepulcro, la estatua funeraria y los escudos de armas.

En el tercer documento se enumeran las indicaciones para la obra del retablo.

En primer término señala: las pinturas deben ser realizadas por Luis Juárez y no otros autores contemporáneos como Prado, Parra o Diego Ramírez.

Para las esculturas designa a Felipe y para los trabajos de ensamblaje a Mendoza, de cuya fama como excelentes oficiales han tenido noticias.

Los tableros deberán narrar pasajes de la vida de la Virgen según lo estipula -con gran precisión- este documento.

En la parte superior del sagrario se pondrá una cruz a la que era muy devoto el maestro de campo.

Los escudos de armas de su primera y segunda esposas y el suyo se colocarian en los extremos del retablo. Otras indicaciones se refieren a los escudos de armas del maestro y a su estatua funeraria.

La solicitud para que se fabriquen los ornamentos del templo de $\mathrm{Za}$ catecas nos revela la falta de mano de obra especializada que originaba una dependencia artística entre las poblaciones del interior y la ciudad de México.

Estas noticias nos permiten ampliar los conocimientos sobre el templo: la solución de la techumbre con madera protegida por el exterior

2 José Rivas Bernárdez. Descripción breve de la muy Noble y Leal Ciudad de Zacatecas. México, Joseph Bernardo del Hogal, 1782, 38.

${ }^{3}$ Los documentos que provienen del Archivo General de la Nación Ramo Jesuitas I, 26, han sido modernizados en su ortografía. 
con lámina de plomo, nos sugiere la trascendencia de la solución que para entonces mostraba el templo de la Casa Profesa.

Los documentos nos indican con claridad el cuidado que el patrono tuvo en la elección de las formas. La temática y los artistas que habían de participar en la construcción del retablo; cuidado que nos habla de una información y de un anhelo de participación. Aunque sabemos que el pintor Pedro de Prado habia trabajado para los jesuitas en Tepozotlán, la preferencia por Luis Juárez nos amplía el catálogo de su obra y nos confirma el éxito que este artifice tenía entre el clero secular y las congregaciones religiosas más recientemente establecidas como la de los carmelitas y mercedarios.

Este colateral mayor es mencionado por Andrés Pérez de Rivas quien dice que se inauguró al mismo tiempo que el templo "un hermosísimo retablo de pincel y fábrica muy prima ..."4 desapareció cuando el templo fue demolido en 1746 para erigir el actual; sin embargo, las tablas de la vida de la Virgen que deben psovenir del antiguo retablo se conservan en el Museo Regional de Guadalupe. Por su calidad, esas tablas nos muestran la razón de la preferencia del patrono del templo de la Compañía de Zacatecas.

Al análisis de los documentos y los vestigios del retablo atestiguan una actitud que se incrementará en los años posteriores en otros empeños donde la voluntad del patrono va a promover las modificaciones de forma y contenido de las obras novohispanas.

Documento I

Carta del Padre Salvador Avilés sobre los gastos de la construcción de la Iglesia

Hoy jueves dia de San Ildefonso fue Dios servido de que se diese conclusión a los negocios de que vine encargado con el buen Maestre de Campo, que se ha animado a gastar su parte en la obra de nuestra iglesia y retablo, veinte y cinco mil pesos como verá vuestra Reverencia por la memoria que va con esto y sin esto toma en sal, novillos y mulas hasta tres mil pesos que le pedí para que el padre Rector pueda con ellos ir

4 Andrés Pérez de Rivas. Crónica e historia religiosa de la Provincia de la Compañia de Jesús en Nueva España. México, Impta. del Sagrado Corazón de Jesús, 1896, I, 296-237. 
Tres mil pesos para comenzar el retablo.

Mil pesos para clavazón, armas fundidas y señal para estatua de villerías.

Padre Avilés. Cómo se ha de distribuir los 4 mil pesos que envió el Maestre de Campo para el retablo. obrando por su parte en la obra, porque ahora envía libranza de mil pesos para este efecto y da orden de buscar quien coja la sal; esta cosecha, y después de haber visto la cantidad de ellos, irá librando el resto de los dos mil pesos con que el padre Rector ha prometido acudir con liberalidad y buen ánimo, a lo que se ha de ir gastando de nuestra parte para el retablo. Ha remitido ya plata a México y libranza de tres mil pesos que dará luego Gabriel de Santillana cuando vuestra Reverencia llegue a México, o antes si vuestra Reverencia escribe al santo Toribio dándole orden de que los cobre y de que se comience a repartir en los que han de tomar a su cargo el pincel, talla y escultura del retablo conforme a la memoria que va con éste y al dibujo o borrón del retablo que va sólo con el ancho y el largo y las figuras del pincel y talla conforme a la devoción del Maestre de Campo, el cual quiere que sea el retablo conforme al de San Jerónimo o al del Carmen de México y que le hagan los oficiales que van nombrados en la memoria.

También libra en Gabriel de Santillana otros mil pesos, para que los quinientos de ellos se gasten para la clavazón, quicialeras, tejuelos, garrones, alcayatas, etcétera, de las dos puertas principales de la iglesia, conforme a lo que el santo Ortiz pedirá que por su cuenta pidió para esto los quinientos pesos que digo. Los otros quinientos pesos son para que se hagan las armas del fundador, de bronce vaciado, y se dé señal para la. brar la estatua del sepulcro de la piedra de villerías, que para todo se envía modelo. De manera que lo que ahora libra en México, son cuatro mil pesos y aguarda el aviso de vuestra Reverencia y el costo del retablo para ir iniciando lo demás. Yo he dado muchas gracias a Dios del grande aliento que ha dado a este caballero, no sólo para lo que ha hecho, sino para lo que desea hacer si fuere Dios servido de librarlo de deudas que con las muchas compras que ha hecho y hace para librarse de pleitos que se le han recrecido de pretensores antiguos de algunas minas de San Martín, han crecido mucho, y espero en Dios que de hoy en adelante ha de tener tanta grosedad de beneficio que pueda hacernos mucho bien, porque siente mucho que de sus deudas le obliguen 
a no poder gastar sólo lo que es menester para nuestra iglesia y está muy alentado a celebrar su dedicación con grandes fiestas y aparato. Vuestra Reverencia se lo agradezca todo como pide tan liberal ánimo, que con lo que ha gastado hasta hoy y los veinte y cinco mil pesos que de nuevo gasta, sienta el gasto suyo en sola la iglesia más de cuarenta y tres mil pesos sin lo que dio de justicia para la fundación, con que se ve que no ha sido tan tenue como piensa Minsiur. Saldré de aquí siendo Dios servido a 25 de éste, con que habré estado en este valle de Súchil doce días que se han gastado bien en esto y en componer algunas causas del Maestre de Campo y otras personas muy a satisfacción de todos, gracias a Dios que guarde a vuestra Reverencia como deseo.

Del Valle enero de 23 de 625.

Hijo humilde de vuestra Reverencia.

Salvador Avilés.

El padre Alarcón llegó hoy aquí a ver al Maestre de Campo y se volvió luego a cerciorarse con Martín de Lizalde y don Gregorio. El santo padre Serrano, con quien viene, se encomienda mucho a vuestra Reverencia.

DOCUMENTO 2

Relación de gastos en la construcción del templo de la Compañía de Zacatecas 1625.

Memoria de lo que el señor Maestre de Campo da para acabar la obra de nuestra Iglesia del Colegio de Zacatecas, desde primero de febrero de este año de 625 , de más de 18 mil pesos que ha gastado su Merced en ella.

Seis mil pesos al maestre de la carpintería para la labor de la madera $6.000 \mathrm{ps}$.

Dos mil pesos al que dio la madera de resto de tres mil que su merced ofreció 
lo que ha gastado y ha de gastar el señor Maestre de Campo en nuestra iglesia de Zacatecas.
De los oficiales canteros y albañiles y peones que son necesarios para acabarla, otros dos mil pesos...

De cincuenta mil ladrillos, mil y doscientos y cincuenta pesos...

La cubierta de plomo toda a su costa, más de cuatro mil pesos.. .

Para la clavazón y aparentes de plomo bronce, para las dos puertas principales, quinientos pesos . . . .

Para el retablo del altar mayor, ocho mil pesos. . . . . . .

Para su sepulcro, mil y doscientos pesos . . . . . . . . . 1.200 ps.

Para las armas de la portada y sepulcro y estatua, más de mil pesos.

No se cuenta el acarreo de la piedra blanca de canteria, ni dos bultos de piedra, de Santiago y San Martín, que quiere labrar a su costa, para que se pongan sobre la portada de la iglesia a las dos esquinas últimas, ni una lámpara que ha prometido a nuestro Santo Padre Ignacio, de peso de cien marcos para el día de la dedicación de la iglesia, que por lo menos monta todo más de mil y quinientos pesos, que juntos a la partida de la suma de la otra plana, son veintisiete mil cuatrocientos y cincuenta pesos.

27,450 ps.

\section{Documento 3}

Indicación para la obra del retablo

Lo que quiere el señor Maestre de Campo acerca del retablo del. altar mayor que hace su Merced, es lo siguiente:

Que la pintura del, hagan Luis Juárez y no Prado (testado: Parra y Diego Ramírez). La escultura Filipe, el ensamblaje Mendoza, porque 
le han dicho que son éstos los más primos oficiales.

Que la pintura y talla sea de los santos que van escritos en el borrón que va con esta memoria, del tamaño largo y ancho del retablo, y se podrán añadir en el banco más figuras a las de los cuatro fundadores de las religiones.

Que sobre el retablo se pongan a los dos lados dos escudos para las armas de su Merced y de su primera y segunda mujer, como irán en dibujo.

Que en el remate del Sagrario se ponga una cruz que se podrá hacer de plata vaciada y dorada, porque ésta es su devoción.

Que el retablo sea como el del Carmen, o San Jerónimo de México, con las columnas jaspeadas si pareciere así al padre provincial.

Este papel que va de esta otra parte es el alto y ancho que puede tener todo el retablo, las calles de escultura son dos con los santos cuyos nombres van señalados en los encazamentos donde han de estar.

Los tableros de pintura son nueve, van señalados los misterios de la Virgen Santisima y en esto no hay que mudar, porque es la voluntad del señor Vicente de Saldívar y él lo escribio.

El Sagrario ha de tener dos cuerpos de alto y sus remates, ha de ser muy bajo de banco, porque sacándose como se saca muchas veces el Santisimo Sacramento, no sea necesario andar con escabel para abrir y cerrar. Los repartimientos que van hechos, no están conforme arquitectura, el maestro lo trazó con orden según las varas que van señaladas de alto $\mathrm{y}$ ancho $\mathrm{y}$ advierte que han de ir las columnas de dos en dos y en los triángulos que se causan al lado del último tablero debajo de armadura, han de ir en cada lado un escudo, asido de dos virtudes con las armas del fundador de medio relieve.

Los cornisamentos y bancos han de venir según su largo en dos piezas, para que puedan venir bien acomodados en cajas y con sus señales en los encajes para que se puedan y sepan armar y bien estibados con sayas y frazadas longas.

El lugar o hueco donde ha de entrar el escudo de las armas en el frontispicio de la portada tiene cinco tercias de vara de medir en cuadro, para que allá se acomoden las armas, de manera que 
el escudo con su timbre y las demás circunstancias quepa dentro de esta medida.

[La estatua ha de ser de piedra de villerias, armada de armas grandes y doradas en el pecho y espaldar y granas.] *

El tamaño de la estatua para el sepulcro ha de ser de una persona de buena estatura, hincada de rodillas y armada ya vuestra Reverencia ha visto el cuerpo y rostro del Maestre de Campo.

[Las armas de frontispicio de la iglesia, ha de ser de bronce doradas, las del sepulcro de madera doradas y ambas serán sólo del Maestre de Campo.]

- Lo que está entre corchetes es de otra letra menuda e intercalada. 